\title{
Treatment of fibromyalgia
}

\section{SUMMARY}

Fibromyalgia is a common, often overlooked, clinical syndrome in general practice. It can be associated with considerable disability, but this is likely to be minimised by early diagnosis and intervention.

Patients with fibromyalgia often have other chronic conditions. Careful clinical evaluation and management of aggravating factors can therefore be beneficial.

A coordinated, patient-centred, multidisciplinary approach to management is required. Patients need education and strategies for self-management of their condition. Non-drug interventions such as physical therapy should be tailored to the individual patient.

Active rehabilitative approaches have primacy in management, but drugs can help to control symptoms. There is evidence to support the use of amitriptyline, duloxetine, milnacipran or pregabalin, but pure opioids should be avoided.

\section{Introduction}

Fibromyalgia is a debilitating and often unrecognised syndrome. It affects $2 \%$ of the population with a peak incidence in middle-aged women.' Despite an incomplete understanding of its pathogenesis, there is increasing evidence for mechanism-based management approaches to this syndrome. ${ }^{2,3}$ These are likely to be more effective if introduced early, making timely diagnosis in general practice even more important.

Fibromyalgia overlaps with other functional somatic syndromes, such as irritable bowel syndrome, chronic fatigue syndrome and temporomandibular joint dysfunction. ${ }^{4}$ While commonly co-occurring with mood and anxiety disorders, research suggests that, although functional somatic disorders are related and potentially interact with psychological conditions, they are independent. $^{5}$

The syndrome is characterised by its hallmark features of widespread somatic pain and deep tissue tenderness, which result from sensitisation of neural pain pathways. ${ }^{6}$ There are also variable combinations of fatigue, sleep disturbance, cognitive dysfunction and psychological distress. These symptoms occur despite the absence of objective abnormalities on clinical assessment.

\section{Pathophysiology}

Fibromyalgia can develop spontaneously, ${ }^{7}$ but is likely to represent a stereotypical, maladaptive, biological response of the body to the cumulative effects of physical or psychological stress in genetically predisposed people. ${ }^{8}$ It is associated with psychiatric and musculoskeletal disorders, leading to poorer outcomes, ${ }^{9,10}$ but it also can occur after an infection. Furthermore, fibromyalgia may occur with increased prevalence in people with chronic medical disorders in general. ${ }^{11}$

Although fibromyalgia has been considered to primarily derive from pathophysiology within the central nervous system, where it is associated with disordered sensory processing, there is growing evidence to suggest that the 'fibromyalgia phenotype' may comprise multiple pathogenetic subsets, including originating, at least in part, within the peripheral nervous system. ${ }^{6,12,13}$ Most cases of fibromyalgia evolve out of persistent regional pain. ${ }^{14}$

\section{Diagnosis}

Diagnostic criteria ${ }^{15}$ have evolved from a recognition that fibromyalgia is a spectrum disorder, both with regards to spatial distribution of pain and symptom involvement and severity. This spectrum has been described as 'fibromyalgianess', and not as a discrete all-or-none disorder, as suggested by the original classification criteria. ${ }^{16}$

Given the multidimensional nature of fibromyalgia, including its association with other chronic medical disorders, clinical assessment in time-poor general practice can be challenging. The condition should be considered as a diagnostic possibility in all cases of persistent, significant musculoskeletal pain, fatigue or sleep disturbance, particularly when such symptoms seem out of proportion to the severity of any background chronic illness. ${ }^{17}$ If any diagnostic doubt exists, referral to a rheumatologist or pain medicine specialist can be considered.

\section{Richard Kwiatek}

Rheumatologist

Northern Adelaide Local

Health Network

South Australia

\section{Keywords}

amitriptyline, duloxetine, fibromyalgia, milnacipran, pregabalin

Aust Prescr 2017:40:179-83 https://doi.org/10.18773/ austprescr.2017.056 
A validated, practical, self-assessment tool based on the diagnostic criteria has been developed (Box 1$)^{18}$ to quantitate the protean symptoms of the syndrome..$^{19,20}$ Scores above certain thresholds ${ }^{20}$ yield reasonable specificity and sensitivity compared to the original classification criteria, ${ }^{16}$ providing assessment by the diagnosing clinician excludes other disorders that fully explain the symptoms. ${ }^{21}$ Examination for deep tissue tenderness, which was required by the old criteria, is now avoided. Investigations are only needed to exclude treatable comorbidities and potential differential diagnoses, such as thyroid dysfunction. ${ }^{22}$

\section{Management}

Spontaneous recovery is unusual so the aims of management are to improve symptoms, function and the quality of life. ${ }^{23}$ There are several steps in the treatment pathway and these should be individually tailored. Treatment is multimodal, multidisciplinary and combines non-pharmacological and pharmacological approaches. ${ }^{2}$

Although the effect sizes for interventions in fibromyalgia are generally small, these are average measures. There are subgroups of patients who will have significant benefits from particular therapeutic approaches. ${ }^{3,24}$ The effect sizes for nonpharmacological approaches tend to be larger than those for drugs, but combinations of drugs have only recently started to be tested. There have been some positive results, ${ }^{25-27}$ emphasising the potential utility of a multimodal approach.

\section{Treatment of aggravating disorders}

The pain sensitisation experienced by patients with fibromyalgia is thought to result from the integrated effects of disturbed ascending facilitatory and

\section{Box 1 Fibromyalgia survey questionnaire}

I. Using the following scale, indicate for each item the level of severity over the past week by checking the appropriate box

0: No problem

1: Slight or mild problems; generally mild or intermittent

2: Moderate; considerable problems; often present and/or at a moderate level

3: Severe; continuous, life-disturbing problems

$\begin{array}{ll}\text { Fatigue } & \square 0 \square 1 \square 2 \square 3 \\ \text { Trouble thinking or remembering } & \square 0 \square 1 \square 2 \square 3 \\ \text { Waking up tired (unrefreshed) } & \square 0 \square 1 \square 2 \square 3\end{array}$

II. During the past 6 months have you had any of the following symptoms?

\begin{tabular}{ll} 
Pain or cramps in lower abdomen & $\square$ Yes \\
Depression & $\square$ No \\
Headache & $\square$ Yes $\quad \square$ No \\
\hline
\end{tabular}

\section{Joint/body pain}

Please indicate below if you have had pain or tenderness over the past 7 days in each of the areas listed below. Please make an $\mathrm{X}$ in the box if you have had pain or tenderness. Be sure to mark both right side and left side separately.

$\begin{array}{lll}\square \text { Shoulder, left } & \square \text { Upper leg, left } & \square \text { Lower back } \\ \square \text { Shoulder, right } & \square \text { Upper leg, right } & \square \text { Upper back } \\ \square \text { Hip, left } & \square \text { Lower leg, left } & \square \text { Neck } \\ \square \text { Hip, right } & \square \text { Lower leg, right } & \\ \square \text { Upper arm, left } & \square \text { Jaw, left } & \\ \square \text { Upper arm, right } & \square \text { Jaw, right } & \\ \square \text { Lower arm, left } & \square \text { Chest } \\ \square \text { Lower arm, right } & \square \text { Abdomen of these areas }\end{array}$


descending inhibitory influences, potentially at multiple levels in the central nervous system. There therefore needs to be careful clinical evaluation and management of disorders which can aggravate this disturbed neurophysiological balance (see Box 2).

\section{Non-pharmacological approaches}

The burden of living with fibromyalgia is higher than with other rheumatic disorders and higher than with most other chronic illnesses. 1,9,10,28 As the medical management of fibromyalgia is often only partially successful, ${ }^{2}$ health professionals need to give patients sustained support to become expert, active self-managers. This is the most important of all interventions to enable successful living with this debilitating multidimensional disorder. However, cognitive dysfunction related to the fibromyalgia, which is often not recognised by treating professionals, can make this process challenging.

Growing evidence suggests self-management skills training is best delivered within a supportive small group setting where education, coping skills training, and cognitive behavioural approaches can be explored. ${ }^{29}$ Skills thereafter can perhaps be consolidated by trained peer mentors. ${ }^{30}$ In Australia effective and sustainable models of care are yet to be developed, although internet and generic chronic pain courses can be used. ${ }^{31,32}$ For all health professionals, an open and patient-centred communication style is strongly recommended. ${ }^{33}$

In general, exercise and psychoeducational approaches have the greatest evidence of efficacy among non-pharmacological therapies, ${ }^{2}$ but they need to be tailored to the individual. Pre-exercise biomechanical assessment and subsequent exercise monitoring by a knowledgeable physical therapist are desirable for all but the mildest cases. Promotion

\section{Box 2 Factors that aggravate pain in fibromyalgia}

Persistent peripheral pain generators (spinal and/ or peripheral arthritis, tendinopathies and myofascial trigger points)

Sleep disorders (obstructive sleep apnoea, restless legs and periodic limb movement disorder)

Obesity (with consequent pain-sensitising effects of meta-inflammation)

Smoking

Opioid-induced hyperalgesia

Statin myopathy

Depression

Catastrophising cognitive style

Psychosocial stressors of daily physical activity can be assisted by use of an actimeter. ${ }^{34}$ Referral to a psychologist should be considered in all patients, particularly those who are more psychologically distressed.

\section{Pharmacological approaches}

Some patients either do not tolerate or benefit from drugs. Drug therapy only has a supportive role in symptom management. All drugs should be started at low doses and cautiously increased. They should be chosen to manage the individual's predominant symptoms, with pain, sleep disturbance and psychological distress being the most amenable to drug therapy. Stop the drug if it provides no benefit.

\section{Antidepressants}

Low-dose amitriptyline has traditionally been the first-line drug for treating pain and sleep disturbance in fibromyalgia. However, the evidence supporting its use is low quality. Studies are small and short-term, but show 4.1 patients need to be treated for one to have at least $50 \%$ pain relief. However, for every 3.3 patients treated, one will have an adverse event. ${ }^{35}$ Tolerance development and weight gain limit the use of amitriptyline, but in a small subgroup it can be very useful in the long term.

Mediators of descending inhibition in the nervous system include serotonin and noradrenaline (norepinephrine).

Their concentrations are reduced in subgroups of patients with fibromyalgia, justifying a trial of a serotonin noradrenaline reuptake inhibitor.

Duloxetine at $60 \mathrm{mg}$ per day has a number needed to treat for at least $50 \%$ pain relief of 8 while the number needed to harm is 18 (all neuropathic conditions pooled) in moderate-quality studies. ${ }^{36}$ It is not approved for fibromyalgia in Australia and its benefit for other core symptoms of fibromyalgia is marginal.

Milnacipran inhibits the reuptake of serotonin and noradrenaline (norepinephrine). It has been approved in Australia for the treatment of fibromyalgia rather than depression. The recommended dose is $100 \mathrm{mg}$ daily in divided doses and requires a private prescription. High-quality evidence shows it has modest efficacy. The number needed to treat for at least 30\% pain relief is 11 with a number needed to harm of $14 .{ }^{37}$ Milnacipran could have a particular role in the management of obese patients, as it appears to have no weightpromoting potential and may cause mild weight loss. ${ }^{38}$

\section{Antiepileptic drugs}

The concentrations of the pain facilitatory neurotransmitters glutamate and substance $P$ in the central nervous system are elevated in fibromyalgia. They are the targets of pregabalin and gabapentin, which have potential pain modulatory, physiological- 


\section{SELF-TEST QUESTIONS}

True or false?

3. Benzodiazepines are the first-line drugs for the sleep disorders associated with fibromyalgia

4. Pure opioids should not be used to treat fibromyalgia

Answers on page 203 sleep-promoting and anxiolytic actions. High-quality evidence shows that for pregabalin the number needed to treat for at least $50 \%$ pain relief is 12 with a number needed to harm of 13. Pregabalin also has a small benefit for sleep, ${ }^{39}$ but weight gain frequently limits its use. Although pregabalin is not listed on the Pharmaceutical Benefits Scheme (PBS) for fibromyalgia, the frequent co-occurrence of neuropathic pain meets PBS requirements.

\section{Other drugs}

There is preliminary evidence from randomised controlled trials of efficacy in subgroups treated with tramadol, ${ }^{40}$ pramipexole ${ }^{41}$ and memantine. ${ }^{42}$ Pure mu-opioid receptor agonists, such as codeine, fentanyl and oxycodone, are contraindicated because of poor clinical response and increased risk of opioid-induced hyperalgesia. ${ }^{40}$ There is no trial evidence of efficacy for paracetamol used alone and there is weak evidence that non-steroidal anti-inflammatory drugs are ineffective. ${ }^{2}$

\section{Conclusion}

Fibromyalgia can be associated with profound, multidimensional disability. Multidisciplinary management is needed. A systematic, patient-centred approach in general practice can yield clinically meaningful improvements in symptom control, function and quality of life of patients with this challenging disorder. Non-pharmacological treatments have an important role.

Drugs can usefully complement an active rehabilitation program. There is some evidence for amitriptyline, duloxetine, milnacipran and pregabalin, but not all patients will benefit. Patients should be monitored for adverse events as these can limit the benefits of drug treatment. $<$

\section{Conflict of interest: none declared}

\section{REFERENCES}

1. Guymer EK, Littlejohn GO, Brand CK, Kwiatek RA Fibromyalgia onset has a high impact on work ability in Australians [PubMed]. Intern Med J 2016;46:1069-74. https://doi.org/10.1111/imj.13135.

2. Macfarlane GJ, Kronisch C, Dean LE, Atzeni F, Häuser W, Fluß E, et al. EULAR revised recommendations for the management of fibromyalgia. Ann Rheum Dis 2017:76:318-28. https://doi.org/10.1136/annrheumdis-2016-209724.

3. Cochrane. Fibromyalgia. www.cochrane.org/search/site/ fibromyalgia [cited 2017 Sep 1]

4. Kato K, Sullivan PF, Pedersen NL. Latent class analysis of functional somatic symptoms in a population-based sample of twins. J Psychosom Res 2010;68:447-53. http://dx.doi.org/10.1016/j.jpsychores.2010.01.010

5. Kato K, Sullivan PF, Evengård B, Pedersen NL. A populationbased twin study of functional somatic syndromes. Psychol Med 2009;39:497-505. http://dx.doi.org/10.1017/ S0033291708003784

6. Sluka KA, Clauw DJ. Neurobiology of fibromyalgia and chronic widespread pain. Neuroscience 2016;338:114-29. https://doi.org/10.1016/j.neuroscience.2016.06.006.

7. Kashikar-Zuck S, Ting TV. Juvenile fibromyalgia: current status of research and future developments. Nat Rev Rheumatol 2014;10:89-96. http://dx.doi.org/10.1038/ nrrheum.2013.177

8. Markkula R, Järvinen $P$, Leino-Arjas P, Koskenvuo M, Kalso E, Kaprio J. Clustering of symptoms associated with fibromyalgia in a Finnish Twin Cohort. Eur J Pain 2009;13:744-50. http://dx.doi.org/10.1016/j.ejpain.2008.09.007

9. Bair MJ, Robinson RL, Katon W, Kroenke K. Depression and pain comorbidity: a literature review. Arch Intern Med 2003:163:2433-45. https://doi.org/10.1001/archinte.163.20.2433.

10. Levy O, Segal R, Maslakov I, Markov A, Tishler M, Amit-Vazina M. The impact of concomitant fibromyalgia on visual analogue scales of pain, fatigue and function in patients with various rheumatic disorders. Clin Exp Rheumatol 2016;34 Suppl 96:S120-4.

11. Wallit B, Nahin RL, Katz RS, Bergman MJ, Wolfe F. The prevalence and characteristics of fibromyalgia in the 2012 National Health Interview Survey. PLoS ONE 10:e0138024. https://doi.org/10.1371/journal.pone.0138024

12. Leinders M, Doppler K, Klein T, Deckart M, Rittner H, Sommer $\mathrm{C}$, et al. Increased cutaneous miR-let-7d expression correlates with small nerve fiber pathology in patients with fibromyalgia syndrome. Pain 2016;157:2493-503. https://doi.org/10.1097/j.pain.0000000000000668.

13. Light AR, Bateman L, Jo D, Hughen RW, Vanhaitsma TA, White AT, et al. Gene expression alterations at baseline and following moderate exercise in patients with chronic fatigue syndrome and fibromyalgia syndrome. J Intern Med 2012;271:64-81. http://dx.doi.org/10.1111/ j.1365-2796.2011.02405.x

14. Bergman S, Herrström P, Jacobsson LT, Petersson IF. Chronic widespread pain: a three year followup of pain distribution and risk factors. J Rheumatol 2002;29:818-25.

15. Wolfe F, Clauw DJ, Fitzcharles MA, Goldenberg DL, Katz RS, Mease P, et al. The American College of Rheumatology preliminary diagnostic criteria for fibromyalgia and measurement of symptom severity. Arthritis Care Res (Hoboken) 2010;62:600-10. http://dx.doi.org/10.1002/ acr.20140

16. Wolfe F, Smythe HA, Yunus MB, Bennett RM, Bombardier C, Goldenberg DL, et al. The American College of Rheumatology 1990 Criteria for the classification of fibromyalgia. Report of the Multicenter Criteria Committee. Arthritis Rheum 1990;33:160-72. http://dx.doi.org/10.1002/ art.1780330203

17. Guymer E, Littlejohn G. Fibromylagia. Aust Fam Physician 2013;42:690-4

18. Häuser W, Jung E, Erbslöh-Möller B, Gesmann M, Kühn-Becker $\mathrm{H}$, Petermann $\mathrm{F}$, et al. Validation of the Fibromyalgia Survey Questionnaire within a cross-sectional survey. PLoS One 2012;7:e37504. https://doi.org/10.1371/ journal.pone.0037504

19. Wolfe F, Clauw DJ, Fitzcharles MA, Goldenberg DL, Häuser W, Katz RS, et al. Fibromyalgia criteria and severity scales for clinical and epidemiological studies: a modification of the ACR Preliminary Diagnostic Criteria for Fibromyalgia. J Rheumatol 2011;38:1113-22. http://dx.doi.org/10.3899/ jrheum.100594

20. Wolfe F, Clauw DJ, Fitzcharles MA, Goldenberg DL, Häuser W Katz RL, et al. 2016 Revisions to the 2010/2011 fibromyalgia diagnostic criteria. Semin Arthritis Rheum 2016;46:319-29. https://doi.org/10.1016/j.semarthrit.2016.08.012.

21. Littlejohn G. Fibromyalgia: honing fibromyalgia diagnosis Nat Rev Rheumatol 2014;10:267-9. http://dx.doi.org/10.1038/ nrrheum. 2014.48

22. Arnold LM, Clauw DJ, McCarberg BH; FibroCollaborative. Improving the recognition and diagnosis of fibromyalgia. Mayo Clin Proc 2011;86:457-64. https://doi.org/10.4065/ mcp.2010.0738.

23. Walitt B, Fitzcharles MA, Hassett AL, Katz RS, Häuser W, Wolfe F. The longitudinal outcome of fibromyalgia: a study of 1555 patients. J Rheumatol 2011;38:2238-46. http://dx.doi.org/10.3899/jrheum.110026 
24. Arnold LM, Cappelleri JC, Clair A, Masters ET. Interpreting effect sizes and clinical relevance of pharmacological interventions for fibromyalgia. Pain Ther 2013;2:65-71. http://dx.doi.org/10.1007/s40122-013-0011-1

25. Mease PJ, Farmer MV, Palmer RH, Gendreau RM, Trugman JM, Wang Y. Milnacipran combined with pregabalin in fibromyalgia: a randomized, open-label study evaluating the safety and efficacy of adding milnacipran in patients with incomplete response to pregabalin. Ther Adv Musculoskelet Dis 2013;5:113-26. http://dx.doi.org/ $10.1177 / 1759720 \times 13483894$

26. Gilron I, Chaparro LE, Tu D, Holden RR, Milev R, Towheed $\mathrm{T}$, et al. Combination of pregabalin with duloxetine for fibromyalgia: a randomized controlled trial. Pain 2016;157:1532-40. http://dx.doi.org/10.1097/ j.pain.0000000000000558

27. Arnold LM, Sarzi-Puttini P, Arsenault P, Khan T, Bhadra Brown P, Clair A, et al. Efficacy and safety of pregabalin in patients with fibromyalgia and comorbid depression taking concurrent antidepressant medication: a randomized placebo-controlled study. J Rheumatol 2015;42:1237-44. https://doi.org/10.3899/jrheum.141196.

28. Perruccio AV, Power JD, Badley EM. The relative impact of 13 chronic conditions across three different outcomes. J Epidemiol Community Health 2007;61:1056-61. https://doi.org/10.1136/jech.2006.047308.

29. Bourgault P, Lacasse A, Marchand S, Courtemanche-Harel R, Charest J, Gaumond I, et al. Multicomponent interdisciplinary group intervention for self-management of fibromyalgia: a mixed-methods randomized controlled trial. PLoS One 2015;10:e0126324. https://doi.org/10.1371/journal.pone.0126324.

30. Harris J, Williams T, Hart O, Hanson C, Johnstone G, Muthana $A$, et al. Using health trainers to promote selfmanagement of chronic pain: can it work? $\mathrm{Br} J \mathrm{~J}$ Pain 2014:8:27-33. https://doi.org/10.1177/2049463713511956.

31. FibroGuide [Internet]. Ann Arbor (MI): Chronic Pain and Fatigue Research Center, University of Michigan Health System; 2014. http://fibroguide.med.umich.edu [cited 2017 Sep 1]

32. Williams DA, Kuper D, Segar M, Mohan N, Sheth M, Clauw DJ. Internet-enhanced management of fibromyalgia: a randomized controlled trial. Pain 2010;151:694-702. https://doi.org/10.1016/j.pain.2010.08.034.
33. Ullrich A, Hauer J, Farin E. Communication preferences in patients with fibromyalgia syndrome: descriptive results and patient characteristics as predictors. Patient Prefer Adherence 2014;8:135-45. http://dx.doi.org/ 10.2147/PPA.S53474

34. Kaleth AS, Slaven JE, Ang DC. Does increasing steps pe day predict improvement in physical function and pain interference in adults with fibromyalgia? Arthritis Care Res (Hoboken) 2014;66:1887-94. http://dx.doi.org/10.1002/ acr.22398

35. Moore RA, Derry S, Aldington D, Cole P, Wiffen PJ Amitriptyline for neuropathic pain and fibromyalgia in adults. Cochrane Database Syst Rev 2012;12:CD008242. https://doi.org/10.1002/14651858.CD008242.pub2

36. Lunn MP, Hughes RA, Wiffen PJ. Duloxetine for treating painful neuropathy, chronic pain or fibromyalgia. Cochrane Database Syst Rev 2014;1:CD007115. https://doi.org/10.1002/14651858.CD007115.pub3

37. Cording M, Derry S, Phillips T, Moore RA, Wiffen PJ. Milnacipran for pain in fibromyalgia in adults. Cochrane Database Syst Rev 2015;10:CD008244. https://doi.org/10.1002/14651858.CD008244.pub3

38. Arnold LM, Palmer RH, Hufford MR, Chen W. Effect of milnacipran on body weight in patients with fibromyalgia. Int J Gen Med 2012;5:879-87. http://dx.doi.org/10.2147/ IJGM.S36444

39. Üçeyler N, Sommer C, Walitt B, Häuser W. Anticonvulsants for fibromyalgia. Cochrane Database Syst Rev 2013;10:CD010782. https://doi.org/10.1002/14651858.CD010782

40. Littlejohn GO, Guymer EK, Ngian GS. Is there a role for opioids in the treatment of fibromyalgia? Pain Manag 2016;6:347-55. http://dx.doi.org/10.2217/pmt-2016-0012

41. Holman AJ, Myers RR. A randomized, double-blind, placebo-controlled trial of pramipexole, a dopamine agonist, in patients with fibromyalgia receiving concomitant medications. Arthritis Rheum 2005;52:2495-505. http://dx.doi.org/10.1002/art.21191

42. Olivan-Blázquez B, Herrera-Mercadal P, Puebla-Guedea M, Pérez-Yus MC, Andrés E, Fayed N, et al. Efficacy of memantine in the treatment of fibromyalgia: a double-blind, randomised, controlled trial with 6-month follow-up. Pain 2014;155:2517-25. http://dx.doi.org/10.1016/j.pain.2014.09.004 